\title{
The Canadian Emergency Department Triage \& Acuity Scale (CTAS) dan Perubahannya: A REVIEW
}

\author{
Aris Widiyanto ${ }^{1}$, Rina Tri Handayani ${ }^{1}$, Mahrifatulhijah ${ }^{1}$, Joko Tri Atmojo ${ }^{1}$, \\ Aquartuti Tri Darmayanti ${ }^{2}$ \\ ${ }^{1}$ STIKES Mamba'ul 'Ulum Surakarta \\ ${ }^{2}$ Program Magister Kesehatan Masyarakat, Universitas Sebelas Maret \\ (widiyanto.aris99@gmail.com)
}

\begin{abstract}
ABSTRAK
Latar Belakang: Pengelolaan pasien yang efisien pada unit gawat darurat membutuhkan tim medis yang mampu mengidentifikasi dengan benar kebutuhan pasien, menetapkan prioritas dan menerapkan perawatan. Kanada berupaya untuk secara lebih akurat mendefinisikan kebutuhan pasien untuk perawatan yang tepat waktu, mengevaluasi tingkat ketajaman tenaga medis dalam menentukan skala prioritas pasien, mengidentifikasi kebutuhan sumber daya dan kinerja terhadap "tujuan" operasi tertentu. Sehingga dibentuk The Canadian Emergency Department Triage \& Acuity Scale (CTAS).

Tujuan: Pada aritkel kali ini penulis tertarik untuk membahas mengenai CTAS berkaitan dengan pembaruan dan juga reliabilitasnya.

Metode: Review ini dilakukan dengan menelusuri database PubMed, EMBASE, dan CINAHL. Kata kunci yang digunakan antara lain: 'Triage in emergency 'ATAU' 'The Canadian Emergency Department Triage \& Acuity Scale (CTAS)' ATAU the Canadian Emergency Department Information System (CEDIS) update" ATAU "the Canadian Paediatric Society (CPS)" ATAU "The Canadian Emergency Department Triage \& Acuity Scale (CTAS) update".Penelusuran ini dilakukan mulai dari Agustus hingga September 2019.

Hasil: Tiga perubahan dalam CTAS yaitu: (1) Perubahan level pada penyakitpenyakit yang berkaitan atau disebabkan oleh demam atau peningkatan suhu. (2) pengubah definisi kelemahan adalah "Setiap pasien yang sepenuhnya bergantung pada perawatan pribadi; siapa yang terikat kursi roda; menderita gangguan kognitif yang membatasi kesadaran mereka tentang lingkungan mereka atau kemampuan untuk menghargai waktu, menunjukkan tanda-tanda cachexia dan kelemahan umum; atau lebih dari 80 tahun kecuali jelas kuat secara fisik dan mental. (3) Pengubah demam 'suhu lebih besar dari 38,5 ${ }^{\circ} \mathrm{C}$ terlihat tidak sehat 'CTAS level 2 dan' suhu lebih tinggi dari $38,5^{\circ} \mathrm{C}$ terlihat baik CT CTAS level 3 akan terbatas untuk anak-anak 3-18 bulan.

Simpulan: CTAS adalah triase dengan 5 level yang pada tahun 2016 terdapat 10 komponen triase yang masih menjadi fokus perhatian dan pembaruan. Hingga terdapat setidaknya 3 pembaruan penting. Namun penelitian telah menunjukan bahwa CTAS merupakan metode yang memiliki reliabilitas atau keandalan yang baik.
\end{abstract}

Kata Kunci: Triase, The Canadian Emergency Department Triage \& Acuity Scale, CTAS

The Canadian Emergency Department Triage \& Acuity Scale (CTAS) dan Perubahannya: A REVIEW (Aris Widiyanto, Rina Tri Handayani, Mahrifatulhijah, Joko Tri Atmojo, Aquartuti Tri Darmayanti) 


\begin{abstract}
Background: Efficient management of patients in the emergency department requires a medical team that is able to correctly identify patient needs, set priorities and implement care. Canada strives to more accurately define patient needs for timely treatment, evaluate the level of sharpness of medical personnel in determining patient priority scale, identifying resource requirements and performance towards certain "goals" of surgery. So that the Canadian Emergency Department Triage \& Acuity Scale (CTAS) was formed.

The Purpose: This study aims to review the Canadian Emergency Department Triage \& Acuity Scale (CTAS).

Method: This review was conducted by searching the PubMed, EMBASE, and CINAHL databases. Keywords used include: 'Triage in emergency' OR 'The Canadian Emergency Department Triage \& Acuity Scale (CTAS)' OR "the Canadian Emergency Department Information System (CEDIS) update" OR "the Canadian Pediatric Society (CPS)" OR " The Canadian Emergency Department Triage \& Accuracy Scale (CTAS) update". This tracking was carried out from August to September 2019.

Results: Three changes in CTAS, namely: (1) Changes in the level of diseases related to or caused by fever or an increase in temperature. (2) modifying the definition of weakness is "Every patient who is totally dependent on personal care; who is wheelchair bound; suffer from cognitive disorders that limit their awareness of their environment or ability to appreciate time, show signs of cachexia and general weakness; or more than 80 years unless clearly physically and mentally strong. (3) Fever modifier 'temperature greater than $38.5^{\circ} \mathrm{C}$ looks unhealthy' CTAS level 2 and 'temperature higher than $38.5^{\circ} \mathrm{C}$ looks good CT CTAS level 3 will be limited to children 3-18 months.

Conclusion: CTAS is a triage with 5 levels which in 2016 there were 10 triage components that are still the focus of attention and renewal. Until there are at least 3 important updates. However, research has shown that CTAS is a method that has good reliability.
\end{abstract}

Keywords: Triage, The Canadian Emergency Department Triage \& Acuity Scale, CTAS

\title{
PENDAHULUAN
}

Peningkatan pasien yang datang pada unit gawat darurat yang diberikan tidak dapat diprediksi dengan sangat akurat. Namun hanya sebagian tertentu dari pasien yang melakukan membutuhkan pertolongan penyelamatan hidup atau kondisi medis yang mendesak, sebagian lain hanya perlu diberikan obat dan perawatan dapat dilanjutkan di rumah (Grossmann et al., 2018; Schellein et al, 2008.

Pengelolaan pasien yang efisien pada unit gawat darurat membutuhkan tim medis yang mampu mengidentifikasi dengan benar kebutuhan pasien, menetapkan prioritas dan menerapkan perawatan. Karena hal tersebut unit gawat darurat sering

The Canadian Emergency Department Triage \& Acuity Scale (CTAS) dan Perubahannya: A REVIEW (Aris Widiyanto, Rina Tri Handayani, Mahrifatulhijah, Joko Tri Atmojo, Aquartuti Tri Darmayanti) 
tertantang untuk menerapkan dan mengembangkan sistem pelayanan termasuk triase (Beveridge et al., 1998).

Di departemen gawat darurat "triase" mengacu pada metode yang digunakan untuk menilai tingkat keparahan cedera atau penyakit dalam waktu singkat setelah kedatangan mereka, tetapkan prioritas, dan pindahkan setiap pasien ke tempat yang sesuai tempat untuk perawatan (Veen et al, 2008).

Kanada berupaya untuk secara lebih akurat mendefinisikan kebutuhan pasien untuk perawatan yang tepat waktu, mengevaluasi tingkat ketajaman tenaga medis dalam menentukan skala prioritas pasien, mengidentifikasi kebutuhan sumber daya dan kinerja terhadap "tujuan" operasi tertentu. Tiga konsep penting termasuk dalam desain The Canadian Emergency Department Triage \& Acuity Scale (CTAS) adalah : 1) Utilitas; 2) Relevansi dan 3) Validitas (Beveridge et al., 1998).

The Society of Rural Physicians of Canada (SRPC) membentuk CTAS National Working Grup untuk mempromosikan penggunaannya di Kanada. Mengingat anak-anak dari neonatus ke remaja tidak mudah dibedakan berdasarkan centric triase dewasa maka Canada Pediatrc Society (CPS) dan CTAS NWG bekerja sama menerbitkan Canadian Pediatric Triage and Acuity Skala pada tahun 2001(Warren et al, 2001).

Pada tahun 2008 ada review kolektif dan pembaruan daftar keluhan the Canadian Emergency Department Information System (CEDIS), CTAS Dewasa dan Pediatrik dan setelah itu diputuskan juga bahwa pembaruan akan dilakukan setiap 4 tahun (Bullard et al., 2017). Sehingga pada artikel kali ini penulis tertarik untuk membahas mengenai CTAS berkaitan dengan pembaruan dan juga reliabilitasnya.

\section{METODE PENELITIAN}

Review ini dilakukan penulis dengan menelusuri database diantaranya PubMed, EMBASE, dan CINAHL untuk mengetahui potensi studi yang memenuhi syarat. Kata kunci yang digunakan antara lain: 'Triage in emergency 'ATAU' 'The Canadian Emergency Department Triage \& Acuity Scale (CTAS)' ATAU the Canadian Emergency Department Information System (CEDIS) update" ATAU "the Canadian Paediatric Society (CPS)" ATAU "The Canadian Emergency Department Triage \& Acuity Scale (CTAS) update".

Penelusuran ini dilakukan mulai dari Agustus hingga September 2019, kriteria artikel yang masuk dalam review kali ini adalah: uji acak terkendali (randomized controlled trial), studi retrospektif, observasional, studi kasus, review, systematic review, dan meta analisis. Artikel akan di eksklusi jika mereka menggunakan skala ini sebagai variabel penjelas, jika mereka fokus pada spektrum terbatas dari penyakit dan gejala atau populasi yang diklasifikasikan dalam batas tertentu tanpa alasan yang jelas.

The Canadian Emergency Department Triage \& Acuity Scale (CTAS) dan Perubahannya: A REVIEW (Aris Widiyanto, Rina Tri Handayani, Mahrifatulhijah, Joko Tri Atmojo, Aquartuti Tri Darmayanti) 


\section{HASIL DAN PEMBAHASAN}

1. Panduan Umum Triase

Perawat triase harus memiliki akses cepat atau mengingat pasien dan mengawasi seluruh area unit gawat darurat setiap saat. Adapun sikap dan keahlian awal yang harus dimiliki perawat berdasarkan (Beveridge et al., 1998) antara lain:

1. Menyapa klien dan keluarga dengan cara empati yang hangat.

2. Melakukan penilaian visual singkat.

3. Mendokumentasikan penilaian.

4. Membagi pasien ke dalam kelompok prioritas menggunakan pedoman yang sesuai.

5. Memindahkan pasien ke area perawatan bila perlu.

6. Memberikan laporan kepada perawat perawatan atau dokter darurat, dokumen yang digunakan untuk melapor diberikan ke dan kembali ke area triase.

7. Membuat pasien / keluarga sadar akan keterlambatan.

8. Menilai kembali pasien.

9. Menginstruksikan pasien untuk memberi tahu perawat tentang perubahan kondisi.

Penugasan tingkat triase yang akurat didasarkan pada:

- Pengetahuan praktis yang diperoleh melalui pengalaman dan pelatihan.

- Identifikasi tanda atau gejala yang benar.

- Penggunaan pedoman dan protokol triase.

Level triase harus dicatat pada semua pasien, selama semua sif. Ini termasuk semua ambulan pasien. Ketika perawat triase telah mengkategorikan lebih dari 3 pasien yang mendesak, itu adalah tanggung jawabnya untuk memprioritaskan pasien dipindah ke ruang perawatan dan mendapatkan penanganan dokter unit gawat darurat. Triase adalah proses yang dinamis: kondisi pasien dapat meningkat atau memburuk selama tunggu masuk ke area perawatan.

\section{Penilaian CTAS}

Berdasarkan (Beveridge et al., 1998) sebagai dasar awal penentuan CTAS, maka penilaian dan juga tindakan berdasarkan triase adalah sebagai berikut:

Level I Resuscitation. Kondisi yang merupakan ancaman terhadap nyawa atau anggota tubuh (atau risiko kemunduran yang segera terjadi) membutuhkan segera intervensi agresif. Saatnya ke dokter SEGERA. Pasien khas: tidak responsif, tanda vital tidak ada / tidak stabil, dehidrasi parah dan gangguan pernapasan parah.

Level II Emergent. Kondisi yang berpotensi mengancam anggota tubuh atau fungsi, membutuhkan intervensi medis yang cepat atau tindakan yang didelegasikan. Waktu untuk penilaian dokter / wawancara $\leq 15$ menit.

Level III Urgent. Kondisi yang berpotensi berkembang menjadi masalah serius yang membutuhkan intervensi darurat. Dapat dikaitkan dengan ketidaknyamanan yang signifikan atau mempengaruhi kemampuan untuk bekerja dan kegiatan hidup sehari-hari. Waktu ke dokter $\leq 30$ menit. 
Level IV Less Urgent (Semi urgen). Kondisi yang berkaitan dengan usia pasien, kesulitan, potensi kerusakan atau komplikasi akan mendapat manfaat dari intervensi atau jaminan dalam 1-2 jam). Waktunya ke dokter $\leq 1$ jam.

Level V Tidak Mendesak No Urgent. Kondisi yang mungkin akut tetapi tidak mendesak serta kondisi yang mungkin menjadi bagian dari masalah kronis dengan atau tanpa bukti kerusakan. Investigasi atau intervensi untuk beberapa penyakit atau cedera ini dapat ditunda atau bahkan dirujuk ke rumah sakit atau sistem perawatan kesehatan lain. Waktunya ke dokter $\leq 2$ jam.

\section{Pembaruan CTAS 2016}

Banyak alasan dan pertimbangan untuk perubahan dalam CTAS Bullard et al., 2017 menjelaskan adapun beberapa bidang-bidang yang menjadi fokus dalam pembaruan guideline antara lain:

1. Review dan kejelasan tentang ketajaman target waktu triase

2. Mengatasi praktik menggunakan CTAS sebagai alat untuk mengalihkan pasien menjauh dari UGD

3. Menghadirkan tambahan pengaduan dan modifikasi CEDIS

4. Pengantar 'penyakit yang berkaitan dengan panas/demam' bersama dengan pengubah khusus

5. Pengubah kehamilan yang direvisi disertai dengan pengantar 'masalah postpartum' dan pengubah khusus

6. Pengenalan pengubah definisi kelemahan baru (Lansia, disabilitas, dan lain sebagainya)

7. Pengembangan pendidikan geriatri baru disertai komponen mengenali tantangan terkait dengan perubahan demografis yang cepat

8. Pembaruan triase anak yang berfokus pada standar demam dan mengenali hipertensi pada anak-anak

10.Memperkenalkan perubahan terencana dalam pendidikan proses, bahan ajar dan sertifikasi CTAS.

Berdasarkan bagian diatas maka dalam CTAS 2016 terdapat beberapa pembaruan antara lain:

1. Pengantar penyakit-penyakit yang berkaitan atau disebabkan oleh demam atau peningkatan suhu, karena perubahan iklim terus menghangatkan atmosfer dan pada tahun 2016 merupakan tahun terpanas, terkait panas kunjungan pasien ke departemen darurat akan menjadi lebih banyak (Glazer, 2005).

Heat stroke adalah keadaan darurat yang mengancam jiwa dan membutuhkan pendinginan dan resusitasi segera pasien dengan kelelahan panas dapat memburuk jika tidak

dievaluasi dan dikelola dengan tepat (Smith, 2005). Perubahan level pada kondisi ni sebagai berikut: 


\begin{tabular}{|llc|}
\hline $\begin{array}{l}\text { Presenting } \\
\text { Complaint }\end{array}$ & Modifiers & $\begin{array}{c}\text { CTAS } \\
\text { Level(s) }\end{array}$ \\
\hline Heat related issue & Respiratory distress & $1-4$ \\
& Hemodynamic status & $1-3$ \\
& Level of consciousness & $1-3$ \\
& Pain score (peripheral) & $1-2$ \\
& Frailty & $3-4$ \\
& Core temperature greater than $41^{\circ} \mathrm{C}$ & 3 \\
& Severe dehydration & 1 \\
& Core temperature 39 ${ }^{\circ}$ - $41^{\circ} \mathrm{C}$ & 2 \\
& Moderate dehydration & 2 \\
& Ongoing heat cramps & 3 \\
& Mild dehydration & 3 \\
& Heat cramps resolving, well & 4 \\
& hydrated & \\
\hline
\end{tabular}

2. Pengenalan pengubah definisi kelemahan baru

Peningkatan kunjungan dan kapasitas di departemen gawat darurat terus terjadi, kelompok-kelompok tertentu yang berisiko termasuk: lansia yang lemah, mereka yang cacat fisik, cacat kognitif, dengan penyakit yang melemahkan, atau tunawisma, jika tidak ditemani akan meningkatkan waktu tunggu karena penanganan mereka membutuhkan waktu yang lama dan bila tidak teliti akan memperburuk keadaan mereka (Bullard et al., 2017).

Studi menunjukkan peningkatan waktu tunggu menyebabkan keterlambatan analgesia, antibiotik yang tertunda, penerimaan ICU yang lebih tinggi dan peningkatan angka kematian untuk semua pasien dengan lansia bahkan lebih rentan (Guttman et al,2011).

Dengan demikian pengubah definisi pasien dengan kelemahan adalah "Setiap pasien yang sepenuhnya bergantung pada perawatan pribadi; siapa yang terikat kursi roda; menderita kognitif gangguan yang membatasi kesadaran mereka tentang lingkungan mereka atau kemampuan untuk menghargai waktu; di akhir perjalanan penyakit terminal; menunjukkan tanda-tanda cachexia dan kelemahan umum; atau lebih dari 80 tahun kecuali jelas kuat secara fisik dan mental (Rockwood et al,2005).

3. Pembaruan triase anak yang berfokus pada standar demam dan mengenali hipertensi pada anak-anak. Pengubah demam 'suhu lebih besar dari 38,5 ${ }^{\circ} \mathrm{C}$ terlihat tidak sehat 'CTAS level 2 dan' suhu lebih tinggi dari $38,5^{\circ} \mathrm{C}$ terlihat baik CT CTAS level 3 akan terbatas untuk anak-anak 3-18 bulan, daripada yang sebelumnya 3-36 bulan (Bullard et al., 2017).

\section{Reliabilitas CTAS}

Perjanjian antar penilai untuk perawat SN1 versus SN2 ((SN1) kappa 0,871 95\% CI $(0,840-0,897)$, dan untuk perawat junior (SN2) kappa 0,871 95\% CI $(0,839$ $0,898)$ ) secara statistik bermakna. Dengan demikian dapat disimpulkan CTAS memiliki keandalan yang baik di antara triase perawat gawat darurat (Mirhaghi, 2015; Atmojo et al, 2019).

The Canadian Emergency Department Triage \& Acuity Scale (CTAS) dan Perubahannya: A REVIEW (Aris Widiyanto, Rina Tri Handayani, Mahrifatulhijah, Joko Tri Atmojo, Aquartuti Tri Darmayanti) 


\section{SIMPULAN DAN SARAN}

\section{Simpulan}

CTAS adalah triase dengan 5 level yang dikembangkan untuk membantu tenaga medis pada unit gawat darurat memprioritaskan pasien berdasarkan ketajaman dan risiko berbasis kolaborasi nasional dan internasional. Sejak awal dikembangkan hingga tahun 2016 terdapat 10 komponen triase yang masih menjadi fokus perhatian dan pembaruan.

Pembaruan yang dibuat anatara lain mengenai penyakit-penyakit yang berkaitan atau disebabkan oleh demam atau peningkatan suhu, karena perubahan iklim terus menghangatkan atmosfer, perubahan definisi kelemahan atau pasien beresiko serta pembaruan triase anak yang berfokus pada standar demam dan mengenali hipertensi pada anak-anak. Meskipun pembaruan terus dilakukan, penelitian telah menunjukan bahwa CTAS merupakan metode yang memiliki reliabilitas atau keandalan yang baik.

\section{Saran}

Kursus pendidikan CTAS baik tatap muka langsung atau online perlu dikembangkan untuk memastikan kejelasan tingkat pemahaman dan kenyamanan menerapkan CTAS.

\section{DAFTAR PUSTAKA}

Atmojo JT, Widiyanto A, T Yuniarti (2019). Reliabilitas sistem triase dalam pelayanan gawat darurat: A review. Jurnal Ilmu Keperawatan Intan Husada. Vol 7 No.2

Beveridge, R. et al. (1998) 'Implementation Guidelines for The Canadian Emergency Department Triage \& Acuity Scale (CTAS) - endorsed by the Canadian Association of Emergency

Bullard, M. J. et al. (2017) 'Revisions to the Canadian Emergency Department Triage and Acuity Scale (CTAS) Guidelines 2016', Canadian Journal of Emergency Medicine, 19(S2), pp. S18-S27.

Grossmann, F. et al. (2018) 'Modern Triage in the Emergency Department', Deutsches Aerzteblatt Online, 107(50).

Guttman A, Schull MJ, Vermeulen MJ, et al. Association between waiting times and short term mortality and hospital admission after departure from emergency department: population based cohort study from Ontario, Canada. BMJ 2011;342:d2983.

Glazer JL. Management of heatstroke and heat exhaustion. Am Fam Physician 2005;71:2133-40.

Mirhaghi, A. (2015) 'Comment on Alquraini et al.: reliability of Canadian Emergency Department Triage and Acuity Scale (CTAS) in Saudi Arabia', International Journal of Emergency Medicine. International Journal of Emergency Medicine, 8(1), pp. 1-2. doi: 10.1186/s12245-015-0090-3.

Rockwood K, Song X, MacKnight C, et al. A global clinical measure of fitness and Frailty in elderly people. CMAJ 2005;173(5):489-95.

The Canadian Emergency Department Triage \& Acuity Scale (CTAS) dan Perubahannya: A REVIEW (Aris Widiyanto, Rina Tri Handayani, Mahrifatulhijah, Joko Tri Atmojo, Aquartuti Tri Darmayanti) 
Schellein O, Ludwig-Pistor F, Bremerich DH: Manchester triage system: Process optimization in the interdisciplinary emergency department. Anaesthesist 2008; 58: 163-70.

Smith JE. Cooling methods used in the treatment of exertional heat illness. Br J Sports Med 2005;39:503-7.

van Veen M, Steyerberg EW, Ruige M, et al.: Manchester triage system in paediatric emergency care: prospective observational study. BMJ 2008; 337: a1501.

Warren D, Jarvis A, Leblanc L; the National Triage Task Force members. Canadian Paediatric Triage and Acuity Scale: implementation guidelines for emergency departments. CJEM 2001;3(Suppl):S1-27. 